\title{
Evaluation of a Preventive Effect of a Lotion on the Formation of Stretch Marks. Quantification of Contractile Forces Developed by Fibroblasts from Early Stretch Marks (Red Color) and from Healthy Surrounding Skin Using GlasBox ${ }^{\text {Plus Device }}$
}

\author{
Carol Courderot-Masuyer ${ }^{*}$, Sophie Robin1', Ferial Fanian², Philippe Humbert² \\ ${ }^{1}$ Bioexigence SAS, Espace Lafayette, Besançon, France \\ ${ }^{2}$ Research and Studies Center on the Integument (CERT), Department of Dermatology, Clinical Investigation Center (CIC \\ INSERM 1431), Besançon University Hospital; INSERM UMR1098, FED4234 IBCT, University of Franche-Comté, Besançon, \\ France \\ Email: *bioexigence@wanadoo.fr
}

How to cite this paper: Courderot-Masuyer, C., Robin, S., Fanian, F. and Humbert, P. (2017) Evaluation of a Preventive Effect of a Lotion on the Formation of Stretch Marks. Quantification of Contractile Forces Developed by Fibroblasts from Early Stretch Marks (Red Color) and from Healthy Surrounding Skin Using GlasBoxPlus Device. Journal of Cosmetics, Dermatological Sciences and Applications, 7, 177-188.

https://doi.org/10.4236/jcdsa.2017.72016

Received: March 7, 2017

Accepted: June 24, 2017

Published: June 27, 2017

Copyright $\odot 2017$ by authors and Scientific Research Publishing Inc. This work is licensed under the Creative Commons Attribution International License (CC BY 4.0).

http://creativecommons.org/licenses/by/4.0/

\begin{abstract}
Stretch marks are cutaneous lesions occurring frequently in weight gain during puberty and early adult life. Previous studies showed that highest contractile forces were developed by fibroblasts from early stretch marks (SMF) compared to those developed by fibroblasts from normal healthy skin (HF) of the same patient. The aim of the present study was to evaluate a possible preventive effect of a topical preparation (containing vitamins $\mathrm{C}$ and $\mathrm{E}$ and botanical extracts including natural extract of Calendula, Aloe Vera and Evening Primrose Oil) on the formation of stretch marks using Glasbox ${ }^{\text {Plus }}{ }^{\circledR}$ device. In the presence of the tested mixture, a significant overall decrease in contractile forces of SMF was noted for 24 hours of measurements compared to control SMF and made it possible to restore their capacity to the same level as HF indicating a possible preventive effect of the tested mixture. The synergistic effects of these components are certainly responsible for the decrease in contractile forces of early stretch marks fibroblasts.
\end{abstract}

Keywords

Stretch Marks, Fibroblasts, Mechanical Forces, Preventive Effect

\section{Introduction}

Stretch marks are cutaneous lesions associated with continuous and progressive 
mechanical stretching of the skin occurring frequently in weight gain during puberty and early adult life [1] [2]. Clinically, the linear lesions evolve with time, passing through an initial red color (red stretch marks) to a typical white stretch mark [3]. Viennet et al. have shown that fibroblasts from early stretch marks were the richest cells in alpha-smooth muscle actin filaments and generated the highest contractile forces compared to than normal fibroblasts using the device GlasBox $^{\circledR}[4]$.

The purpose of this study was to evaluate the relaxing effect of a lotion containing vitamins $\mathrm{C}$ and $\mathrm{E}$ and botanical extracts on fibroblasts obtained from early stretch marks in comparison with normal fibroblasts from neighboring skin of the same patient.

The tested lotion is a mixture of components with anti-inflammatory properties such as panthenol [5], shea butter [6], niacinamide [7], calendula [8]. Some of them have also moisturing properties such as panthenol, avocado oil, cocoa seed butter and aloe vera [9] and vitamin E. The mixture also provides components with antioxidant properties such as vitamin $\mathrm{E}$ and vitamin $\mathrm{C}$ and two oils, avocado oil rich source of vitamin $\mathrm{E}$ and sweet orange oil, rich source of naturally vitamin $\mathrm{C}$.

\section{Materials and Method}

\subsection{Tested Product}

The tested lotion (Pregnacare ${ }^{\circledast}$ lotion, Vitabiotics Ltd, London) contains vitamins $\mathrm{C}$ and $\mathrm{E}$ and botanical extracts including natural extract of Calendula, Aloe Vera and Evening Primrose Oil.

\subsection{Fibroblasts Isolation and Culture}

Early stretch marks fibroblasts (SMF) and healthy fibroblasts (HF) were obtained from a woman (23 years old). After thawing, cells were grown in Dulbecco's modified Eagle's medium supplemented with $10 \%$ of bovine serum, 40 $\mathrm{mg} / \mathrm{l}$ of gentamicin and $2 \mathrm{mg} / \mathrm{l}$ of fungizone (DMEMc), in an incubator at $37^{\circ} \mathrm{C}$, $5 \% \mathrm{CO}_{2}$ and $95 \%$ air. Culture medium was changed twice a week and cells were subcultured when confluence was reached, by trypsinization. Fibroblasts from subculture 3 to 8 were used in this study. According to Burgess, the fibroblasts cultivated in passages lower than 8 , preserve their in vivo characteristics [10].

\subsection{Viability Studies}

Fibroblast viability in monolayers was assessed using the 3-(4,5-dimethylthiazol2-yl)-2,5 diphenyltetrazolium bromide (MTT) dye-reduction assay. All cultures were set up in 10 wells. Fibroblasts from early stretch marks fibroblasts and healthy skin were placed in 96-well microliter plates at a cell density of $5 \times 10^{3}$ cells per well. After 24 hours of incubation, the mixture of vitamin C, E and botanical extracts in different concentrations was added to the culture medium of fibroblasts. The two types of fibroblasts were seeded with active mixture for 24 hours. Then MTT was added. The extraction buffer was added after 4 hours. 
Absorbance of each well was assessed using a Multiscan Ex (Thermo, France) equipped with a $550 \mathrm{~nm}$ filter. Cell viability was evaluated after $24 \mathrm{~h}$ of lotion exposure. Several percentages of a mixture of lotion $(0.000001 \% ; 0.000005 \%$; $0.00001 \%$; 0.00005\%; 0.0001\%; 0.0005\%; 0.001\%; 0.005\%; 0.01\%; 0.05\%; 0.1\%).

\subsection{GlasBox ${ }^{\mathrm{Plus} \circledast}{ }^{\text {Device }}$}

The cell chamber is composed of eight rectangular culture wells in which lattices develop (Figure 1). Two opposite beams hung down into each well at a distance of $27 \mathrm{~mm}$ apart. The lattice is attached to this sensor through a grid directly etched on the lower part of each beam. The beams have a system to detect their own deformation using optic fibers. This deformation is proportional to the contractile forces developed by fibroblasts. The signal is collected by a computer, which include a specific program to give directly the forces in real time.

Collagen lattice (or dermal equivalent) preparation and measurement of contractile forces.

Fibroblasts were suspended just before confluence with a trypsin-EDTA (1 X) solution. A sample was taken to determine the number of cells obtained. The suspension was centrifuged and a final count was performed before bringing the living fibroblasts to the concentration of $8 \times 10^{5} \mathrm{cells} / \mathrm{ml}$. Fibroblasts were embedded three-dimensionally in hydrated collagen gels using a modified version of the technique developed by Bell. Briefly, $2 \mathrm{ml}$ of $1.76 \mathrm{X}$ concentrated DMEM medium (with gentamycin, $0.1 \mathrm{~N} \mathrm{NaOH}$ and $\mathrm{NaHCO}_{3}$ ) were added to $1 \mathrm{ml}$ of a solution of type I Murid Collagen ( $2 \mathrm{mg} / \mathrm{ml}$ ) (Jacques Boy, Reims, France), and to $0.33 \mathrm{ml}$ of the suspension of living fibroblasts in the culture medium. The lattice mixture was poured into a rectangular culture well of the GlasBox ${ }^{\text {Plus }}{ }^{\circledR}$ and polymerized in less than $5 \mathrm{~min}$ at $37^{\circ} \mathrm{C}$. Two milliliters of culture medium were added. The GlasBox ${ }^{\text {Plus }}{ }^{\circledR}$ was then placed into a humidified incubator at $37^{\circ} \mathrm{C}$, and force measurements were started immediately for 24 hours. The results were expressed as contractile forces (arbitrary unit) according to the time or expressed as AUC (area under the curve) allowing a quantification of contractile forces developed by fibroblasts from early stretch marks and healthy neighboring skin in the presence of active mixture.

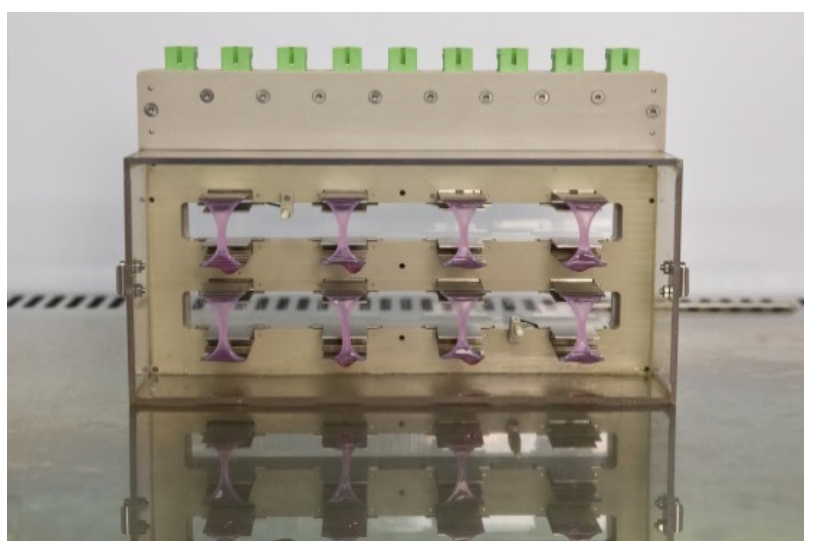

Figure 1. GlasBox ${ }^{\text {Plus }}$. 
Each GlasBox ${ }^{\text {Plus }}{ }^{\circledR}$ curve was fitted with GraphPad Prism ${ }^{\circledR}$ software to determine the area under the curve (AUC), the maximum of contraction (Max) and the slope (speed of contraction). Area under the curve gives information on the global contraction of fibroblasts during the experiment. Maximum of contraction corresponds with the plateau of the fitted curve.

The following four groups were used:

Control HF: no lotion

Control SMF: no lotion

Group HF: lotion

Group SMF: lotion.

\subsection{Statistical Analysis}

The results shown were expressed as the mean \pm s.e.m. A variance analysis with one factor was performed for the study of cytotoxicity, area under the curve, maximum of contraction and the slope and was followed if necessary by a Fisher test. A variance analysis with two factors (group versus control and time) was carried out for the study of measurement of contractile forces followed if necessary by a Fisher test. A p value less than 0.05 was considered significant.

\section{Results}

\subsection{Cytotoxicity Studies}

Viability of HF was significantly decreased with $0.0005 \%, 0.001 \%$ and $0.01 \%$ of active mixture (Table 1). All the concentrations tested until $0.0001 \%$ could be used for the following experiments.

No significant difference was observed with the addition of lotion on SMF. However, cell viability was slightly decreased with $0.0005 \%, 0.001 \%$ and $0.1 \%$ (Table 2).

Table 1. Viability of healthy fibroblasts in the presence or not of lotion after 24 hours of culture. (Mean \pm sem; ${ }^{\star *} p<0.01$ and ${ }^{\star * *} p<0.001$ versus Control).

\begin{tabular}{ccc}
\hline \multirow{2}{*}{ Lotion \% } & \multicolumn{2}{c}{ Viability (\%/Control) } \\
\cline { 2 - 3 } Control & Mean & sem \\
\hline $\mathbf{0 . 0 0 0 0 0 1}$ & 100.0 & 3.9 \\
$\mathbf{0 . 0 0 0 0 0 5}$ & 96.0 & 4.9 \\
$\mathbf{0 . 0 0 0 0 1 0}$ & 92.4 & 5.1 \\
$\mathbf{0 . 0 0 0 0 5 0}$ & 96.0 & 4.3 \\
$\mathbf{0 . 0 0 0 1 0 0}$ & 91.6 & 4.5 \\
$\mathbf{0 . 0 0 0 5 0 0}$ & 98.4 & 4.2 \\
$\mathbf{0 . 0 0 1 0 0 0}$ & $80.1^{* *}$ & 4.8 \\
$\mathbf{0 . 0 0 5 0 0 0}$ & $76.0^{* * *}$ & 3.8 \\
$\mathbf{0 . 0 1 0 0 0 0}$ & 82.0 & 1.9 \\
$\mathbf{0 . 0 5 0 0 0 0}$ & $79.1^{* *}$ & 4.3 \\
$\mathbf{0 . 1 0 0 0 0 0}$ & 81.3 & 3.6 \\
& 87.1 & 6.8 \\
\hline
\end{tabular}


Table 2. Viability of stretch marks fibroblasts in the presence or not of lotion after 24 hours of culture. (Mean \pm sem).

\begin{tabular}{ccc}
\hline \multirow{2}{*}{$\begin{array}{c}c \\
\%\end{array}$} & Viability (\%/Control) \\
\cline { 2 - 3 } Control & 100.0 & sem \\
\hline $\mathbf{0 . 0 0 0 0 0 1}$ & 93.3 & 4.4 \\
$\mathbf{0 . 0 0 0 0 0 5}$ & 106.4 & 5.8 \\
$\mathbf{0 . 0 0 0 0 1 0}$ & 107.4 & 3.6 \\
$\mathbf{0 . 0 0 0 0 5 0}$ & 106.4 & 5.2 \\
$\mathbf{0 . 0 0 0 1 0 0}$ & 111.3 & 3.9 \\
$\mathbf{0 . 0 0 0 5 0 0}$ & 92.6 & 3.6 \\
$\mathbf{0 . 0 0 1 0 0 0}$ & 84.7 & 7.1 \\
$\mathbf{0 . 0 0 5 0 0 0}$ & 96.9 & 5.9 \\
$\mathbf{0 . 0 1 0 0 0 0}$ & 94.8 & 4.5 \\
$\mathbf{0 . 0 5 0 0 0 0}$ & 101.9 & 3.9 \\
$\mathbf{0 . 1 0 0 0 0 0}$ & 83.5 & 3.6 \\
\hline
\end{tabular}

So the concentration $0.0001 \%$ of lotion was used for the following experiments on HF and SMF.

\subsection{Force Generation}

We used the device GlasBox ${ }^{\text {Plus }}{ }^{\circledR}$ to measure contractile forces in tense collagen lattices formed with HF and SMF. The measurements of contractile forces of both fibroblasts lines were recorded continuously for 24 hours.

Contractile forces of SMF were significantly increased compared to HF ( $p<$ 0.001) (Figure 2).

In the presence of $0.0001 \%$ of lotion, no modification of contractile forces of HF was observed (Figure 3).

On the contrary, an overall decrease in contractile forces of SMF was noted for 24 hours of measurements $(p<0.001)$ compared to control SMF and made it possible to restore their capacity to the same level as HF (Figure 4).

The calculated area under the curve and maximum of contraction showed a significant increase in the control group of SMF compared to control of HF ( $p<$ 0.001) (Figure 5).

In the presence of active mixture, no significant difference of AUC and maximum of contraction in HF and SMF were observed in comparison to their respective control group (data not shown).

\section{Discussion}

Skin is physiologically tensed. During aging, strain forces inside the skin, decreases and subsequent relaxation are responsible for wrinkles formation. These forces also play an important role in wound healing and are disturbed in various pathologies such as stretch marks [4]. 


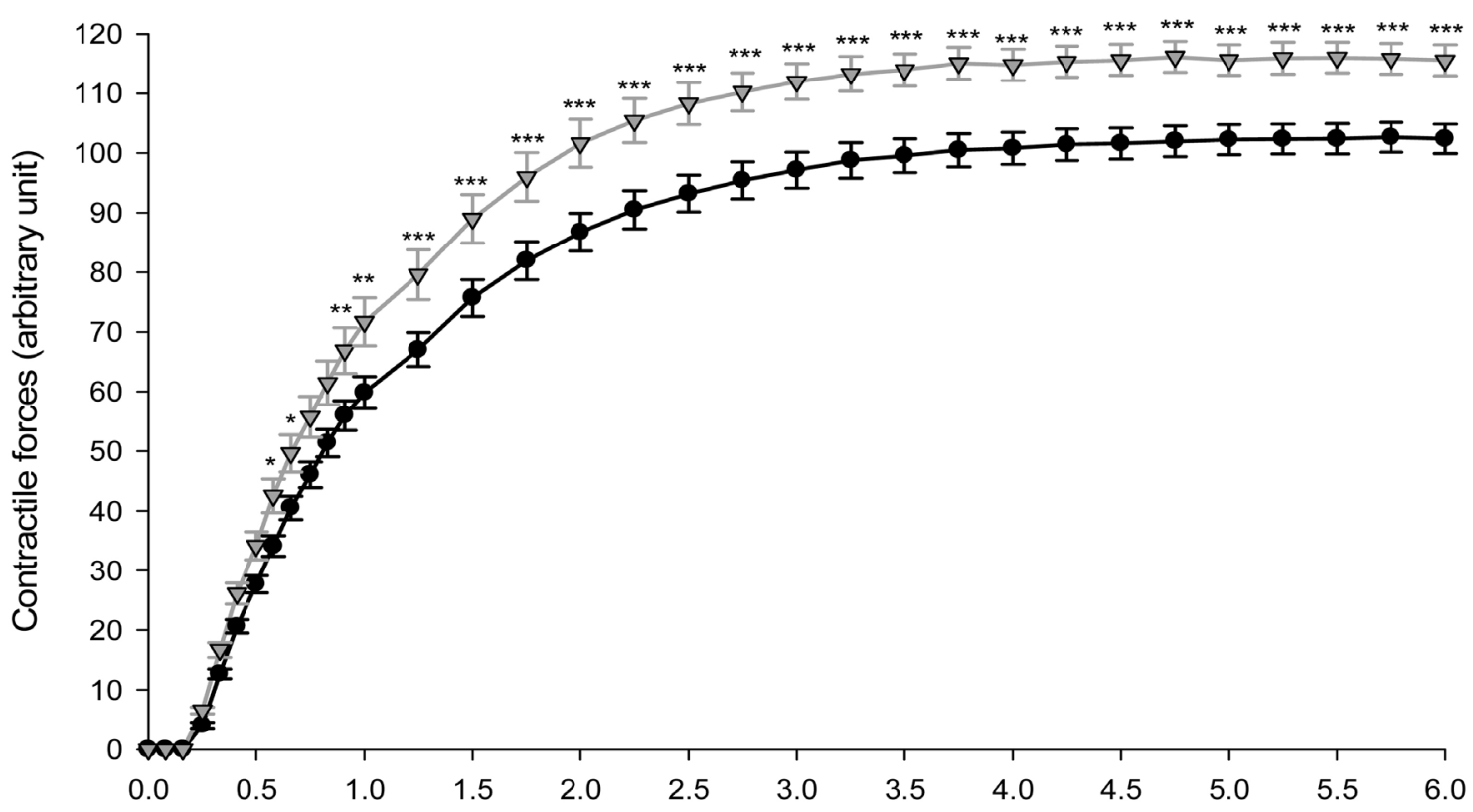

(a)

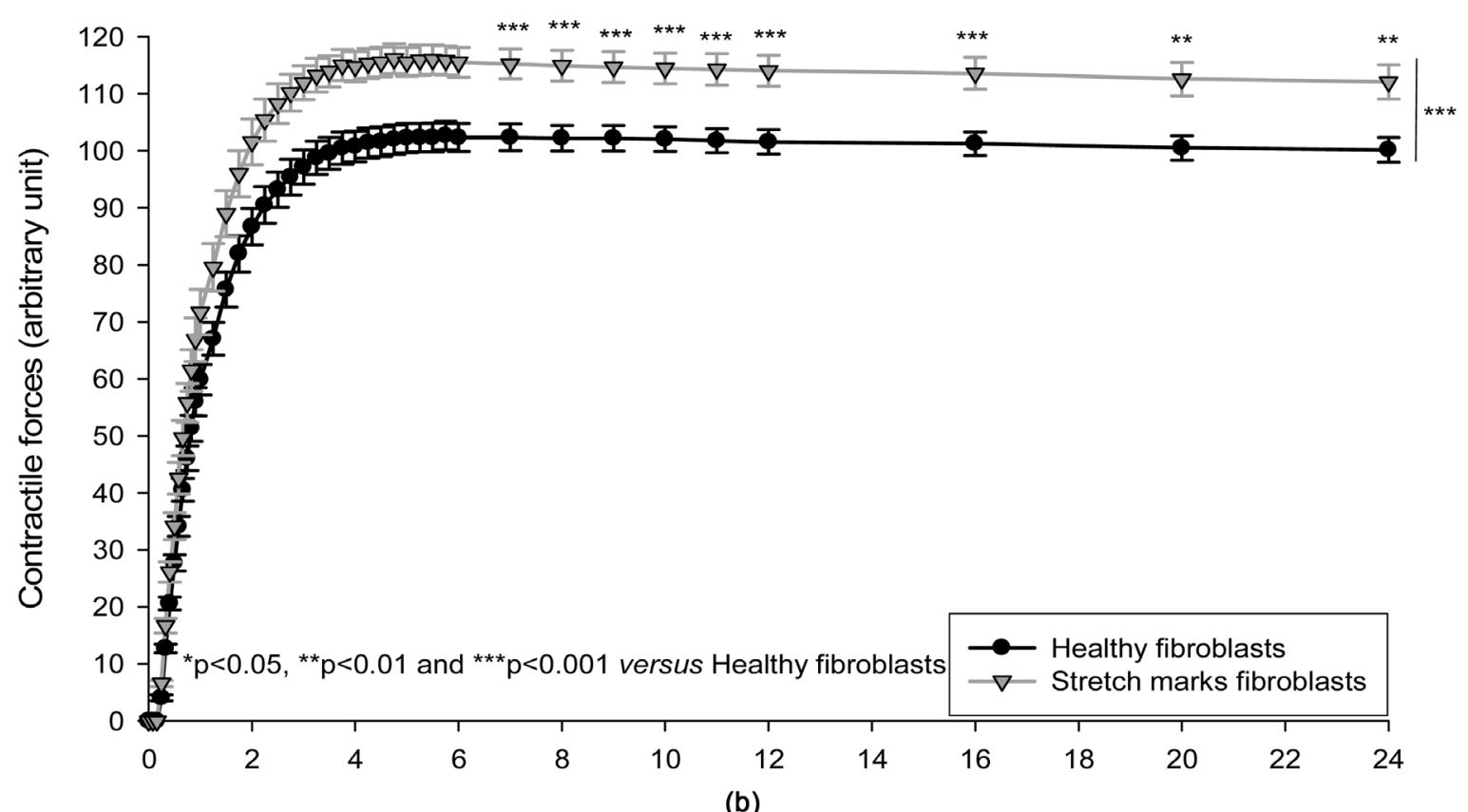

Figure 2. Contractile forces developed by healthy and stretch marks fibroblasts ((a): First 6 hours of measurement; (b): Totality of the measurement).

Mechanical strain originates from the dermis, the medium layer of the skin, which the main components are fibroblasts, and a network of collagen fibers. When fibroblasts bind collagen fibers, they stretch the network and create strain forces. In normal conditions, the interfibrillar substance is highly viscous and there is no slipping or separation of collagen fibers [11]. Our laboratory developed a new device GlasBox ${ }^{\text {Plus }}$ which is able to quantify the development of contractile forces of human fibroblasts in accordance to time and in the presence or not of cosmetic actives or topical preparations. This device makes it possible 


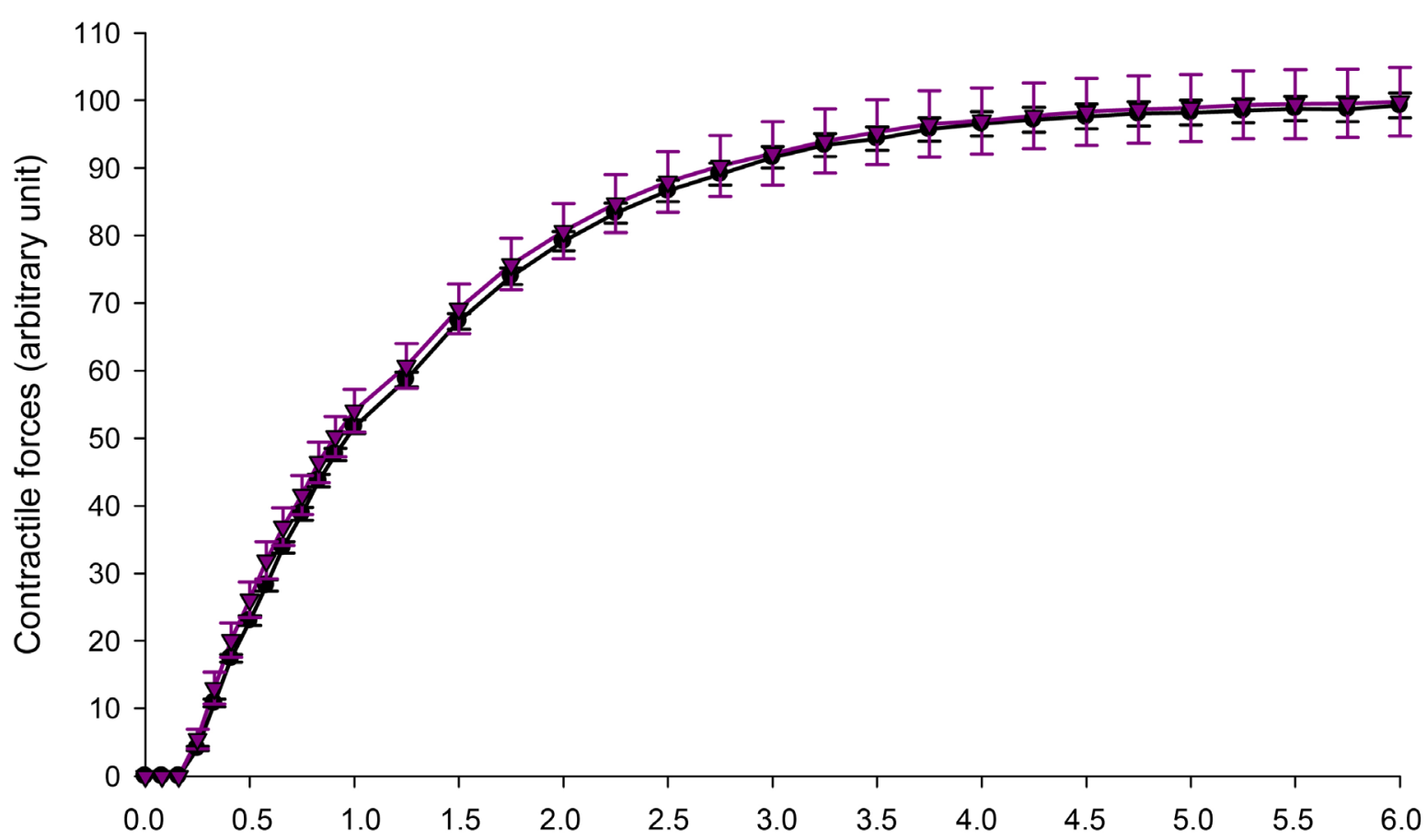

(a)

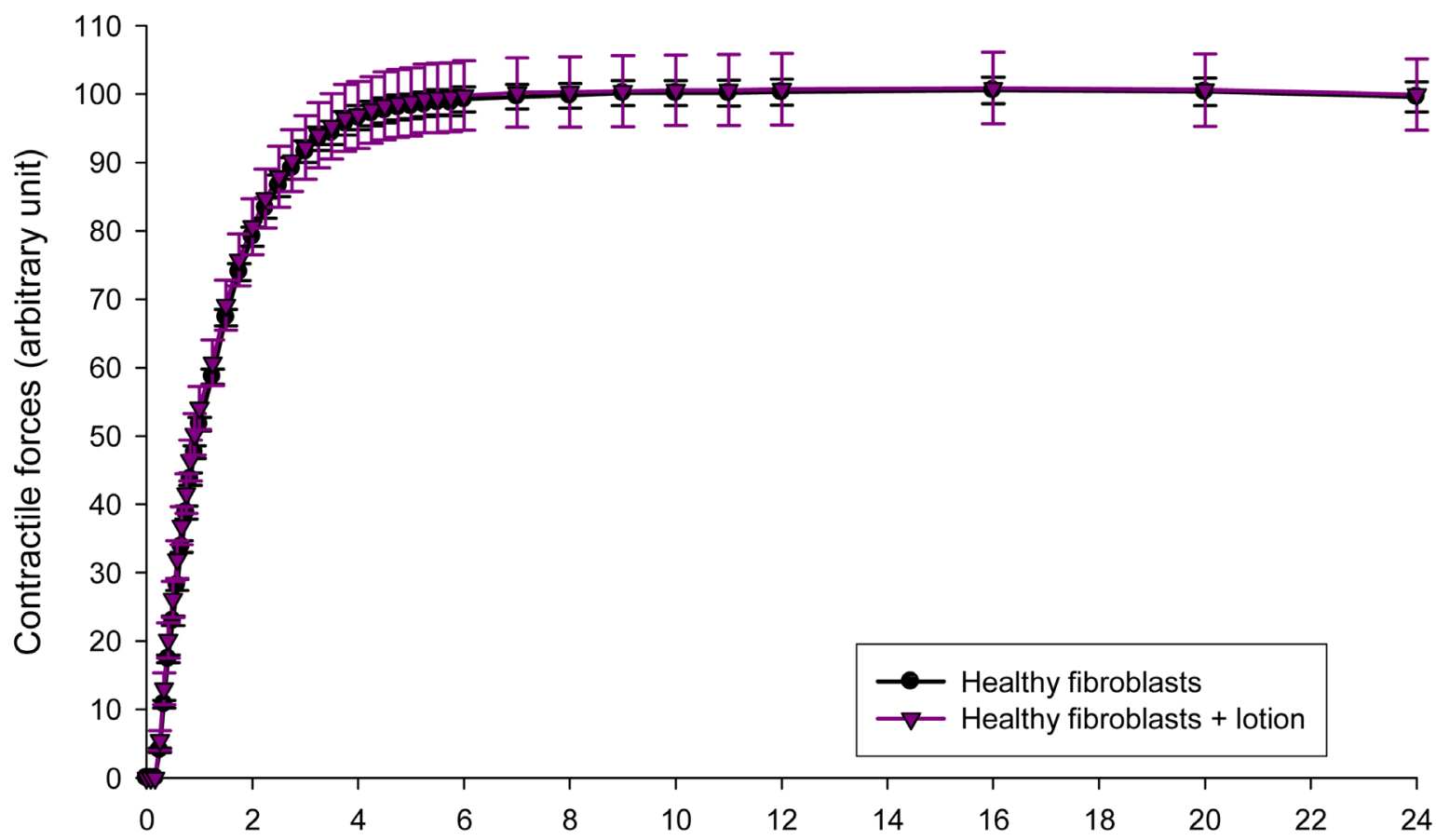

(b)

Figure 3. Contractile forces developed by healthy fibroblasts with and without lotion at $0.0001 \%$ ((a): First 6 hours of measurement; (b): Totality of the measurement).

to quantify the forces generated in tense collagen lattices (or tense dermis equivalent) composed of various fibroblast lines. It has already shown that the behavior of fibroblasts depended on the pathogenesis. Glasbox ${ }^{\text {Plus }}$ device was also used to compare the mechanical activity of different populations of fibroblasts 

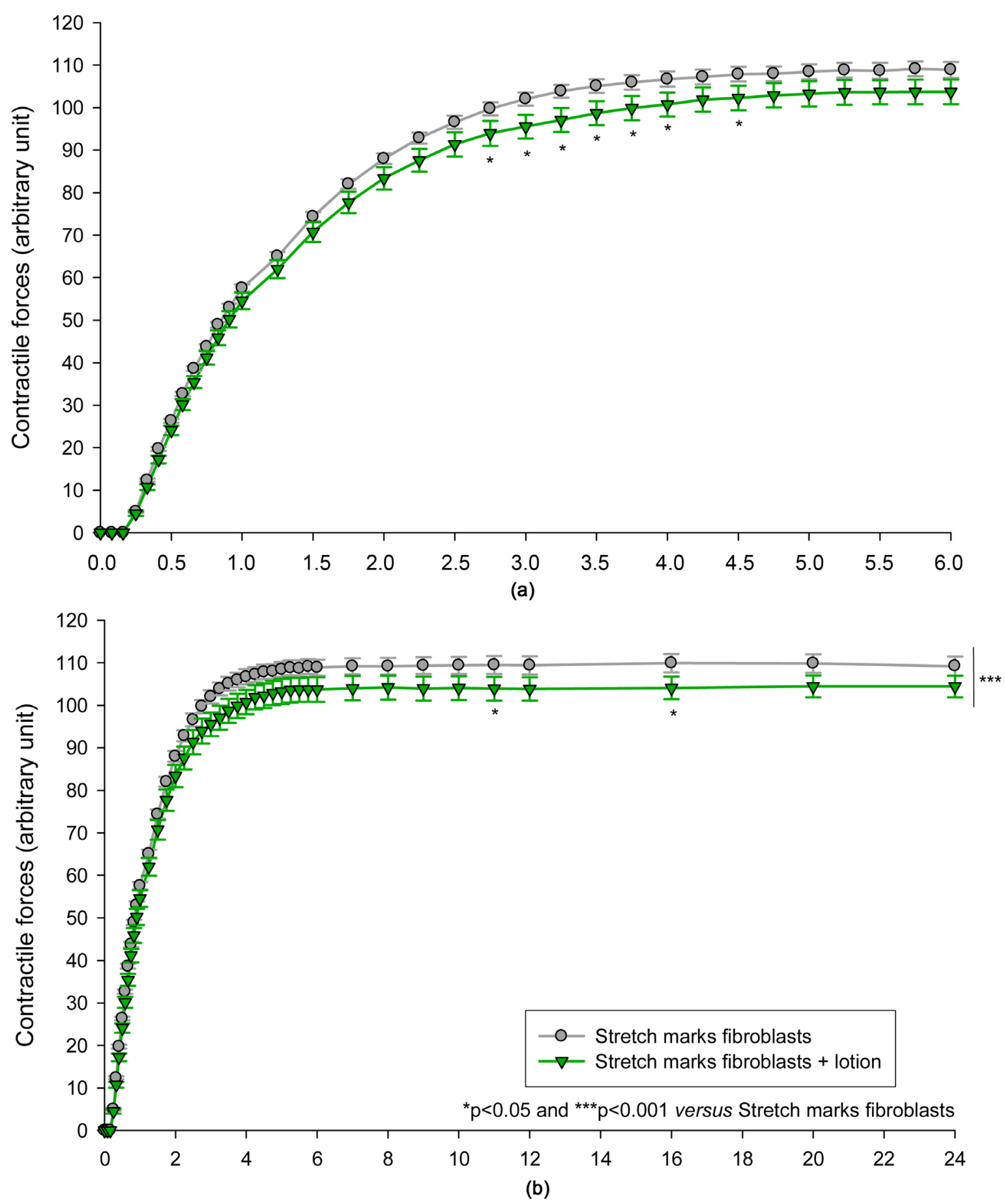

Figure 4. Contractile forces developed by stretch marks fibroblasts with and without lotion at $0.0001 \%$ ((a): First 6 hours of measurement; (b): Totality of the measurement).

derived from venous ulcers and fibroblasts of normal tissues of the same patients. Contractile forces developed by the ulcer centre and ulcer edge were significantly greater than those of normal fibroblasts [12]. A previous study also showed that the contractile activity of fibroblasts irradiated with UVA decreased in comparison with normal fibroblasts [13]. This system can be used to examine the relationship between cellular contraction, cell proliferation and collagen 

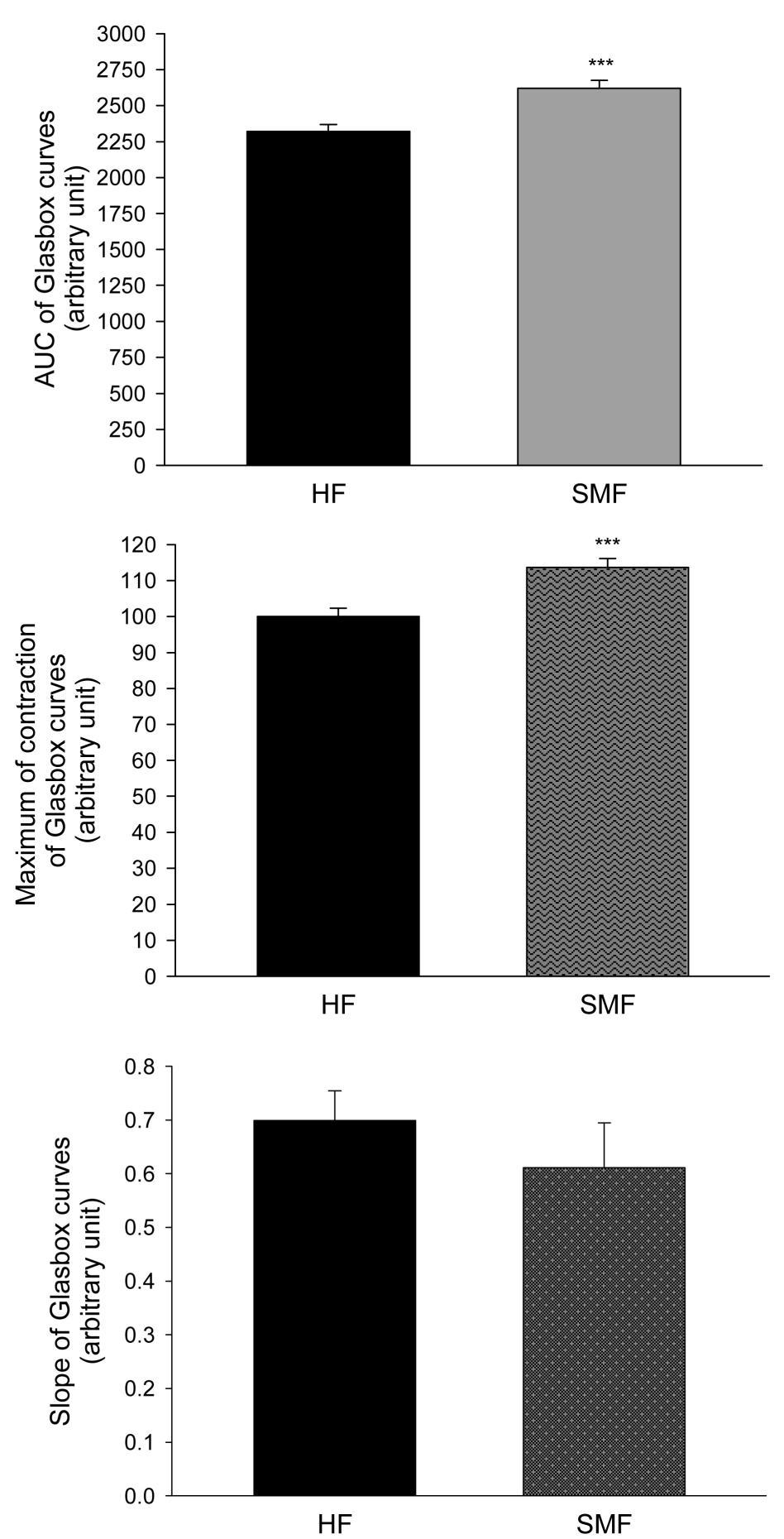

Figure 5. AUC, maximum of contraction and slope calculated from GlasBox $^{\text {Plus }}{ }^{\circledR}$ curves for healthy (HF) and stretch marks (SMF) fibroblasts.

production which is important in understanding for the mechanism for cell regeneration in aging.

In the case of stretch marks, strain forces are so important that the collagen mechanism is disrupted and irreversible sliding and separation of fibers occur. During the early stage of stretch marks (red color), fibroblasts respond to the mechanical tension by expressing $a \mathrm{SM}$ actin and producing strong contractile 
forces [4].

Stretch marks occur in $50 \%$ to $90 \%$ of women during pregnancy or not. They appear as red or purple lines or streaks that fade slowly to leave pale lines or marks on the skin. The abdomen, breasts or thighs are commonly affected. They are a source of significant anxiety for women, impacting on their quality of life. The exact cause of stretch marks is unclear. The stretch marks do not disappear entirely; therefore any treatment which prevents them would be welcomed by many women. Amongst possible treatments of stretch marks, treatment with an onion extract cream with Centellaasiatica and hyaluronic acid demonstrated an improvement in the appearance of stretch marks when they are still in reddish stage. People using this cream said that their marks faded after 12 weeks of daily use [14]. One study, involved 80 pregnant women, indicated that, compared to placebo, the topical application of the active cream containing centallaasiatica extract, alpha tocopherol and collagen-elastin hydrolysates was associated with less women developing stretch marks [15]. Another study showed an improvement of clinical appearance of early stretch marks after 2 months of treatment with topical $0.1 \%$ tretinoin compared to the vehicle [16]. A cosmetic oil formulation has also shown to improve the appearance of stretch marks. This oil contains a mixture of potential actives in a mineral oil such as retinyl palmitate, tocopherol and glycine soja associated to lavandulaaugustifolia, rosmarinus officinalis, calendula officinalis and bisabolol. The improvements were observed after 4 weeks of treatment and peaked at six to eight weeks [17].

The aim of the present study was to evaluate a possible preventive effect of a topical preparation on the formation of stretch marks using Glasbox ${ }^{\text {Plus }}{ }^{\circledR}$ device. Our results are in accordance with those of Viennet et al. [4]; highest contractile forces were developed by fibroblasts from early stretch marks (SMF) compared to those developed by fibroblasts from normal healthy skin (HF) of the same patient. In the presence of the tested mixture, a significant overall decrease in contractile forces of SMF was noted for 24 hours of measurements compared to control SMF and made it possible to restore their capacity to the same level as HF indicating a possible preventive effect of the tested mixture. The mixture contains molecules with antiinflammatory properties such as panthenol, shea butter, niacinamide and calendula which have also regenerative properties, molecules with antioxidant properties such as vitamins $\mathrm{C}$ and $\mathrm{E}$ or oils rich in vitamin $\mathrm{E}$ (avocado oil) and sweet orange oil, rich in vitamin C. The synergic effects of these components are certainly responsible for the decrease in contractile forces of early stretch marks fibroblasts, observed in our device. These results suggest a preventive effect of the tested lotion on the occurrence of stretch marks.

\section{Acknowledgements}

This study was funded by VitabioticsLtd.

\section{References}

[1] Moretti, G., Rebora, A. and Guarrara, M. (1976) Striae Distensae: How and Why 
They Are Formed. In: Moretti, G. and Rebora, A., Eds., Striae Distensae, Brocades, Milan, 87-96.

[2] Shuster, S. (1979) The Cause of Striae Distensae. Acta Dermato-Venereologica Supplement (Stockholm), 59, 161-169.

[3] Sisson, W.R. (1954) Colored Striae in Adolescent Children. Journal of Pediatrics, 45, 520-530. https://doi.org/10.1016/S0022-3476(54)80114-4

[4] Viennet, C., Bride, J., Armbruster, V., Aubin, F., Gabiot, A.C., Gharbi, T. and Humbert, P. (2005) Contractile Forces Generated by Striae Distensae Fibroblasts Embedded in Collagen Lattices. Archives of Dermatological Research, 297, 10-17. https://doi.org/10.1007/s00403-005-0557-9

[5] Ebner, F., Heller, A., Rippke, F. and Tausch, I. (2002) Topical Use of Dexpanthenol in skin Disorders. American Journal of Clinical Dermatology, 3, 427-433. https://doi.org/10.2165/00128071-200203060-00005

[6] Akihisa, T., Kojima, N., Kikuchi, T., Yasukawa, K., Tokuda, H., Masters, E., Manosroi, A. and Manosroi, J. (2010) Anti-Inflammatory and Chemopreventive Effects of Triterpene Cinnamates and Acetates from Shea Fat. Journal of Oleo Science, 59, 273-280. https://doi.org/10.5650/jos.59.273

[7] Niren, N.M. (2006) Pharmacologic Doses of Nicotinamide in the Treatment of Inflammatory Skin Conditions: A Review. Cutis, 77, 11-16.

[8] Okoh, O.O., Sadimenko, A.P., Asekun, O.T. and Afolayan, A.J. (2008) The Effects of Drying on the Chemical Components of Essential Oils of Calendula officinalis L. African Journal of Biotechnology, 7, 1500-1502.

[9] Barcroft, A., Myskja, A. and Reinolds, T. (2003) Properties of Stabilized Aloe Vera. In: Barcroft, A., Myskja, A. and Reinolds, T., Eds., Aloe Vera: Nature's Silent Healer, BAAM Publishing Ltd., London, 1-16.

[10] Burgess, M.L., Terracio, L. and Borg, T.H. (2002) Differential Integrin Expression by Cardiac Fibroblasts from Hypertensive and Exercise Trained Rat Hearts. Cardiovascular Pathology, 11, 78-87. https://doi.org/10.1016/S1054-8807(01)00104-1

[11] Archer, C.B. (2004) Functions of the Skin. In: Burns, T., Breathnach, S., Cox, N. and Griffiths, C. Eds., Rook's Textbook of Dermatology, 7th Edition, Vol. 1, Blackwell Science, Malden, MA, 4.1-4.12. https://doi.org/10.1002/9780470750520.ch4

[12] Viennet, C., Armbruster, V., Gabiot, A.C., Gharbi, T., Bride, J. and Humbert, P. (2004) Comparing the Contractile Properties of Human Fibroblasts in Leg Ulcers with Normal Fibroblasts. Journal of Wound Care, 13, 358-361.

https://doi.org/10.12968/jowc.2004.13.9.26706

[13] Robin, S., Courderot-Masuyer, C., Tauzin, H., Guillon, S., Gaborit, J., Harbon, S. and Humbert, P. (2012) Evaluation of Protective and Restoring Effects of a Mixture of Silanols on Photoaging. Use of a Device Allowing the Quantification of Contractile Strengths of Human Fibroblasts after UVA Irradiation. International Journal of Cosmetic Science, 34, 311-317. https://doi.org/10.1111/j.1468-2494.2012.00716.x

[14] Draelos, Z.D., Gold, M.H., Kaur, M., Olayinka, B., Grundy, S.L., Pappert, E.J. and Hardas, B. (2010) Evaluation of an Onion Extract, Centrallaasiatica, and Hyaluronic Acid Cream in the Appearance of Striarubra. Skinmed, 8, 80-86.

[15] Mallol, J., Belda, M.A., Costa, D., Noval, A. and Sola, M. (1991) Prophylaxis of Striae gravidarum with a Topical Formulation. A Double Blind Trial. International Journal of Cosmetic Science, 13, 51-57. https://doi.org/10.1111/j.1467-2494.1991.tb00547.x

[16] Kang, S., Kim, K.J., Griffiths, C.M.E., Wong, T.Y., Talwar, H.S., Fisher, G.J., Gordon, D., Hamilton, T.A., Ellis, C.N. and Voorhees, J.J. (1996) Topical Tretinoin (Re- 
tinoic Acid) Improves Early Stretch Marks. Archives of Dermatology, 132, 519-526. https://doi.org/10.1001/archderm.1996.03890290053007

[17] Summers, B. and Lantegan, B. (2009) The Effect of a Topically-Applied Cosmetic Oil Formulation on Striae Distensae. South African Family Practice, 51, 332-336. https://doi.org/10.1080/20786204.2009.10873874

Submit or recommend next manuscript to SCIRP and we will provide best service for you:

Accepting pre-submission inquiries through Email, Facebook, LinkedIn, Twitter, etc. A wide selection of journals (inclusive of 9 subjects, more than 200 journals)

Providing 24-hour high-quality service

User-friendly online submission system

Fair and swift peer-review system

Efficient typesetting and proofreading procedure

Display of the result of downloads and visits, as well as the number of cited articles Maximum dissemination of your research work

Submit your manuscript at: http://papersubmission.scirp.org/

Or contact jcdsa@scirp.org 